ISPEC Tarım Bilimleri Dergisi

5(4): 881-889, 2021

(C) Telif hakk ISPEC'e aittir

Arasturma Makalesi
E-ISSN:2717-7238

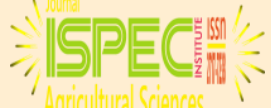

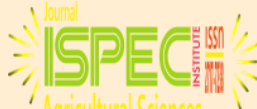

www.ispecjournal.com
ISPEC Journal of Agr. Sciences

5(4): 881-889, 2021

Copyright $\mathbb{C}$ ISPEC

$\underline{\text { Research Article }}$
Hüsnü AKTAŞ ${ }^{*}$

${ }^{1}$ Mardin

Artuklu

Üniversitesi/K1ziltepe Meslek

Yüksekokulu/Bitkisel Ve Hayvansal

Üretim Bölümü/Tohumculuk

Teknolojisi Programı

1ORCID:0000-0001-6943-2109

*Sorumlu yazar:

husnuaktas@artuklu.edu.tr

DOI

https://doi.org/10.46291/ISPECJASv ol5iss4pp881-889

Alınış (Received): 28/05/2021

Kabul Tarihi (Accepted): 30/06/2021

Anahtar Kelimeler

Midyat, mercimek, verim, kalite

Keywords

Midyat, lentil, yield, quality

\section{Midyat Yerel Kırmızı Mercimeği (Lens culinaris Medik.) Konusunda Ön Çalışma}

\section{Özet}

$\mathrm{Bu}$ çalışma geçmişi yüzyıllara dayanan, tat, aroma bakımından üstün özellikler taşıması dolayısıyla Mardin ili ve çevresinde yaşayan tüketicilerce en çok tercih edilen Midyat Kırmızı Mercimek Yerel çeşidinin bazı tarımsal karakterler ve kalite özellikleri bakımından karakterize edilmesi amacıyla yapılmıştır. Deneme 2020-21 yetiştirme sezonunda Kızıltepe ilçesi çiftçi tarlasında 2 tekerrürlü olarak yürütülmüştür. Varyans analiz sonuçlarına göre incelenen tüm özellikler için genotipler arasındaki fark istatistiki olarak önemli bulunmuştur. Tane verimi bakımından Fırat-87 çeşidi $250 \mathrm{~kg} / \mathrm{da}$ ilk sırada yer alırken ve Midyat-1 populasyonu ise $220 \mathrm{~kg} /$ da ile diğer standart çeşitlere yakın değere sahip olmuştur. Yerel popülasyonlar standart çeşitlere göre geç çiçeklenme ve olgunlaşma özelliklerine sahip olurken, ilk bakla yüksekliği, bitki boyu bakımından standart çeşitlerden daha düşük değerlere sahip oldukları tespit edilmiştir. Midyat- 1 populasyonu kuru ağırlık (5.05 g), Midyat-2 populasyonu yaş ağırlık (9.55 g), Midyat-3 populasyonu kuru hacim $(58.0 \mathrm{ml})$ ve yaş hacim $(112.5$ ml) özellikleri bakımından tüm standart çeşitlerden daha yüksek değerlere sahip olmuşlardır. Elde edilen sonuçlar, Midyat yerel kırmızı mercimek çeşidinin kaliteli kırmızı mercimek çeşitlerinin geliştirilmesi için büyük bir potansiyele sahip olduğunu ve islah çalışmalarında direk olarak veya genitör olarak kullanılabilecek değerli bir genetik kaynak olduğunu göstermiştir.

Pre-Study for Red Lentil Landraces (Lens culinaris Medik.) of Midyat Province

\section{Abstract}

This study was conducted to characterization of historical Midyat Red Lentil landraces that prefered by consumers because of desirable traits for taste and aroma interms of some agronomic and quality traits. Experiment was performed with 2 replications in 2020-21 growing season at field farmer, K1z1ltepe province. Examined traits of genotypes were found statisticaly signifigant. Firat-87 was most yielding variety for grain yield $\left(250 \mathrm{~kg} \mathrm{da}^{-1}\right)$ while Midyat-1 landrace $\left(220 \mathrm{~kg} \mathrm{da}^{-1}\right)$ showed similar perfromance to checks for grain yield. Observatons indicated that landraces had a lower plant height and first pod, while checks had earlier flowering and maturity time compare to Red lentil landraces. Among the red lentil landraces, Midyat-1 population for dry seed weight $(5.05 \mathrm{~g})$, Midyat-2 for wet seed weight $(9.55 \mathrm{~g})$ showed higher values than modern varieties while, Midyat-3 showed desirable traits for dry volüme $(58.0 \mathrm{ml})$ and wet volüme $(112.5$ $\mathrm{ml})$. Results indicated that red lentil landraces have huge potential to improve high quality varieties and could be used as genitor in breeding programs. 


\section{GİRIS}

Mercimek (Lens culinaris Medik) kendine döllenen ve diploid yedi kromozom çiftine $(2 \mathrm{n}=14)$ sahip, Leguminosae takımının Papilionatae familyasına bağlı Vicieae oymağına mensup bir baklagil bitkisidir (Bahl ve ark., 1993). Mercimeğin Güneydoğu Anadolu Bölgesi ve Suriye'nin Kuzey batısını içine alan Verimli Hilal'de kültüre alındığı ve geçmişinin M.Ö 70008000 yılarına dayandığ 1 birçok araştırmacı tarafindan bildirilmektedir (Bahl ve ark., 1993). Mercimek (Lens), yabani progenitörü Lens culunaris subp sp. Orienlatalise (Boiss)'den yararlanarak kültüre alınmış ve günümüzde de bu yabani mercimek türlerini Güneydoğu Anadolu'nun bazı alanlarında doğal olarak yetişmektedir. (Vlachostergios ve ark., 2018; Özer ve Kaya, 2018). Kırmız1 Mercimek ise mercimek türleri içerisinde özel bir öneme sahiptir. Son 20 y1l öncesine kadar dünyanın belirli bölgelerinde sınırlı olarak yetiştirilebilen Kırmızı Mercimek, bazı ıslah çalışmaları ile geliştirilmiş çeşitler sayesinde, günümüzde Kanada başta olmak üzere bazı ülkelerin sadece mikro klimatik özellikler taşıyan alanlarında üretilebilmektedir (Alabay, 2019). Kırmızı Mercimeğin birincil gen merkezi olması nedeniyle Güneydoğu Anadolu bu anlamda çok önemli bir alandır (Erman ve ark., 2021).

Türkiye'de son 20 yıl içerisinde sslah edilmiş birkaç modern Kırmızı Mercimek çeşitlerinin (Fırat-87, Şakar, Çağıl, Seyran, Çiftçi) sertifikalı tohumlukları Güneydoğu Anadolu Bölgesinde büyük oranda yayılmış ve domine duruma geçmiştir (Düzgün ve Toğay, 2021). Bu durum yerel kırmızı mercimek çeşitlerinin çoğunun yok olmasına ve çok küçük alanda ve az sayıda yerel çeşit üretimine sebep olmuştur (Biçer ve Şakar, 2011). Bu yerel çeşitler Güneydoğu Anadolu Bölgesinin marjinal tarım alanları olarak kabul edilen, eğimli, toprak derinliği düşük, toprak verimliliği düşük alanlarında çok az sayıda da olsa yetiştirilmektedir (Toklu ve ark, 2009). Bölgede bu amaçla teknik gezi yapan araştırmacılar, özellikle Fırat-87 çeşidinin bu yerel buğday çeşitlerinin yerini almaya başladığını ve var olan sınırlı sayıda yerel çeşidin de yok olma ile yüz yüze olduğunu bildirmektedirler (Toklu ve ark., 2009; Çokkızgın ve Anlarsal, 2007). Güneydoğu Anadolu'da bu anlamda halen yerel çeşit üretimine devam eden alanlardan bir tanesi de Mardin iline bağlı olan Midyat, Ömerli, Savur ilçeleri örnek olarak verilebilir. Özellikle lokal olarak Midyat ilçesi ve çevresine adaptasyonu yüksek, tat, koku aroma, su alma kapasitesi ve pişme kalitesinin yüksek olduğu ve en çok aranan ve tercih edilen Midyat yerel mercimek çeşidi bu anlamda dikkat çekmektedir. Yapmış olduğumuz bitki toplama ve teknik gezide, çiftçi, zahireci, mercimek işlemepaketleme işletmeleri, restoran sahipleri, yerel ve yabancı tüketiciler, Midyat Yerel Mercimeğinin tercih edilme nedenini açıklarken; Mardin, Kızıltepe ve Diyarbakır ilindeki büyük mercimek üreticileri dahil kendi ürettikleri mercimek ürünlerini değil de, Midyat ilçesinde üretilmiş bu yerel çeşidi ev tüketimi için tercih ettiklerini; Midyat Mercimeğinin sarı renk değerinin ve kuru madde oranının yüksek, pişme süresinin kısa olduğunu, tane su alma kapasitesinin yüksek olduğunu, mercimek işleme prosesinde istenilen özelliklere sahip yüksek randımanlı olduğunu, tat, koku ve aroma bakımından iyi değerlere sahip olduğuna dair sözlü anlatımlarda bulunmuş ve bu yerel mercimek konusunda Diyarbakır, Mardin ili ve ilçelerinde yüzyıllara dayanan bir geçmişinin ve öyküsünün olduğuna dair veriler elde edilmiştir. Yaptığımız ön çalışma ile modern 1slah çeşitlerine göre daha iri ve dolgun, tane rengi koyu kahve ve kahverenginin değişik tonlarında, beneksiz veya çok az benekli, futbol ve yaprak üretim tipine ve tüketime uygun bir çeşit veya popülasyon olduğu tarafımızca tespit edilmiştir. $\mathrm{Bu}$ yerel çeşit konusunda şuana kadar bir araştırma yapılmamış olması, akademik anlamda bir çalışmaya konu olmamış olması bu yerel çeşit konusunda bir ön çalışma yapmamızı gerekli kılmıştır. 
$\mathrm{Bu}$ amaçla, Midyat ilçesinden toplanmış olan Midyat Kırmızı Mercimek çeşidine ait 3 beldeden toplanmış 3 populasyon ve 4 adet modern ıslah çeşidi toplanmış ve bu çeşitler bazı kalite parametreleri bakımından değerlendirilmiştir. $\mathrm{Bu}$ çalışmada amaç, Midyat Mercimeğinin modern 1slah çeşitleri ile karşılaştırıp, üstün olan özelliklerinin ortaya konması ve gelecek yıllarda yapılacak proje ve islah çalışmaları için bir germplazm tanımlaması yapmak ve bu değerli genetik kaynağ akademik çalışmalara konu etmektir.

\section{MATERYAL ve YÖNTEM}

Midyat ilçesine bağlı olan Budakl1, Acurlu ve Söğütlü beldelerindeki çiftçi tarlalarından toplanmış Midyat Yerel Mercimeğine ait 3 populasyona ait tohum örneği ve aynı bölgeden 4 farklı modern 1slah çeşidine ait örnekler ve Kızıltepe ilçesinden iki modern çeşide ait örnek bazı kalite kriterleri bakımından değerlendirilmek üzere çalışmada materyal olarak kullanılmıştır.

\section{Tasnif}

Midyat ilçesine bağılı Budaklı (Midyat1 populasyonu), Acurlu (Midyat-2 populasyonu) ve Sögütlü (Midyat-3 populasyonu) beldelerinde mercimek ekili tarlalar ziyaret edilip, üreticilerin beyanları esas alınarak aynı beldelerden hem Midyat Yerel Mercimeği hem de modern islah çeşitlerine ait tohum örnekleri, aynı zamanda Kızıltepe ilçesine bağlı 3 köyden tohum örnekleri alınmış ve kalite analizleri için kullanılmışlardır.

\section{Deneme ve bakım işlemleri}

$\mathrm{Bu}$ çalışma 2020-2021 yetiştirme sezonunda 4 standart çeşit (Çağıl, Seyran, Fırat-87 ve Şakar) kırmızı mercimek (Lens culinaris Medik.) çeşitleri ile Midyat ilçesine özgü 3 yerel popülasyonun (Midyat-1 populasyonu), Acurlu (Midyat-2 populasyonu) ve Sögütlü (Midyat-3 populasyonu) bazı agronomik ve kalite özelliklerinin araştırılması amacıyla Kızıltepe koşullarında, tesadüf blokları deneme desenine göre 2 tekerrürlü olarak kurulmuştur. Metre kareye 250 tohum, parsel uzunluğu $5 \mathrm{~m}$, her parselde 6 adet sira sira arası $20 \mathrm{~cm}$ olacak şekilde ekimler 25.11.2020 tarihnde yapılmıştır. Denemede; tane verimi (kg/da), \% 50 çiçeklenme gün sayısı (gün), fizyolojik olum (gün), bitki boyu (cm), ilk bakla yüksekliği $(\mathrm{cm})$, bitkide dal sayısı (adet), bitkide bakla sayısı (adet), 1000 tane ağırlığı (g), kuru ağırlık (g),yaş ağırlık (g), vb özellikleri Gıda Tarım ve Hayvancılık Bakanlığının, talimatına göre yapılmıştır (https://www.tarimorman.gov.tr/).

\section{Agronomik gözlemler kalite analizleri}

Çiçeklenme gün sayısı (gün), olgunlaşma gün sayısı (gün) bitki boyu $(\mathrm{cm})$, ilk bakla yüksekliği $(\mathrm{cm})$ bin tane ağırlığı (gr) ve tane verimi $(\mathrm{kg} / \mathrm{da})$ gözlemleri Gıda Tarım ve Hayvancılık Bakanlığı Tohumluk Tescil ve Sertifikasyon Müdürlüğü'nün belirtmiş olduğu talimata göre alınmıştır. (Anonim, 2021a) Bazı kalite parametreleri analizi aşağıda belirtildiği şekilde yapılmıştır.

\section{Yaş ağırlık/ kuru ağırlık}

Kırık olmayan tanelerden boyutuna bakmaksızın rastgele 100 tane seçilerek ağırlığı ölçülerek kuru ağırlık olarak $g$ olarak kaydedildi. 100 tane mercimek 150 $\mathrm{ml}$ saf olan beherde atılıp 16 saat bekletildi, süre sonunda kurutma kağıdı ile kurulanıp tartıldı. Sonuç yaş ağırlık olarak g cinsinden kaydedildi (Williams, 1988).

\section{Yaş hacim/ kuru hacim analizleri}

Mercimeklerde yapılan kuru-yas hacim ölçümlerinde 100 adet örneğin üzerine 50 $\mathrm{ml}$ su eklenerek mezürde hacimleri tespit edilecek. 16 saat su dolu beherlerde bekletildikten sonar suyu süzdürülerek ayni örnekler tartılıp yas ağırlıkları, ardından $100 \mathrm{ml}$ su ilavesiyle yas hacimleri ölçülöüştür (Williams, 1988).

\section{İstatstiki analizler}

İstatistiksel analizler, tesadüf blokları deneme desenine göre JMP 5.1 paket programından yararlanılarak yapılmıştır. Ayrica, ortalamalar arasındaki farklılık gruplandırması için L.S.D. (AÖF) (Least Significant Difference- Asgari Önemli Fark) testinden yararlanılmıştır. 
Çizelge 1. Deneme alanının toprak özellikleri

\begin{tabular}{|l|l|l|}
\hline Analiz Adı & Sonuç & Derecesi \\
\hline Saturasyon & 60.0 & Killi-Tınlı \\
\hline pH & 7.75 & Hafif Alkali \\
\hline Toplam Tuz & 0.04 & Tuzsuz \\
\hline Kireç & 12.05 & Orta Kireçli \\
\hline Organik Madde \% & 2.01 & Orta \\
\hline Alınabilir Fosfor & 10.05 & Çok Yüksek $(\mathrm{kg} / \mathrm{da})$ \\
\hline Alınabilir Potasyum & 140.8 & Yüksek $(\mathrm{kg} / \mathrm{da})$ \\
\hline
\end{tabular}

Deneme alanına ait toprak örneklerinin fiziksel ve kimyasal analiz sonuçları Çizelge 1'de gösterilmiştir. Yapılan incelemede deneme alanının bünyesinin killi-tınlı olduğu, $\mathrm{pH}$ değerinin 7.75 , tuz oranının $\% 0.04$ olduğu, organik madde içeriğinin $\%$ 2.01, kireç oranının \% 12.05, fosfor miktarının $10.05 \mathrm{~kg} / \mathrm{da}$ olduğu, potasyum miktarının $140.8 \mathrm{~kg} / \mathrm{da}$ olduğu tespit edilmiştir. Çalışmanı yürütüldüğü sezona ait iklim verileri Çizelge 2.' de verilmişstir. Bu verilere göre 2021 y1lı Mart, Nisan ve mayıs aylarında uzun yıllara göre çok düşük bir yağış görülmüş olup, kuraklık stresinin yaşanmıştır.

Çizelge 2. Denemenin yürütüldüğü alana ait iklim verileri

\begin{tabular}{|c|c|c|c|c|c|c|c|c|c|c|c|c|c|}
\hline & Yıllar & Ocak & Şubat & Mart & Nisan & Mayıs & Haziran & Temmuz & Ağustos & Eylül & Ekim & Kasım & Aralık \\
\hline $\begin{array}{c}\text { Sıcaklık } \\
\left({ }^{\circ} \mathbf{C}\right)\end{array}$ & 2020 & 3.6 & 3.8 & 10.7 & 14.1 & 19.9 & 26.2 & 31.5 & 29.9 & 29.3 & 22.8 & 12.0 & \\
\hline & 2021 & 3.4 & 3.5 & 10.2 & 15.1 & 20.01 & 27.01 & 32 & 28.3 & 27.3 & & & \\
\hline & $\begin{array}{c}\text { U.Y. } \\
\text { Ort. }\end{array}$ & 6.9 & 9.0 & 12.2 & 16.0 & 21.7 & 28.5 & 32.1 & 30.9 & 26.2 & 20.5 & 13.3 & 8.1 \\
\hline Yăğı̦ (mm) & 2020 & 75.9 & 102.8 & 157.3 & 51.6 & 30.5 & 31.5 & 4 & 0 & 0 & 0 & 35.7 & 65 \\
\hline & 2021 & 65 & 60 & 35 & 21 & 15 & 5 & 0 & 0 & 0 & - & - & - \\
\hline & $\begin{array}{c}\text { U.Y. } \\
\text { Ort. }\end{array}$ & 36.03 & 33.15 & 59.18 & 37.62 & 38.77 & 3.53 & 0.73 & 0.20 & 1.47 & 24.51 & 33.29 & 33.53 \\
\hline Nem $(\%)$ & 2020 & 71.9 & 71.4 & 65 & 59.7 & 43.4 & 26 & 20.6 & 22.1 & 20.6 & 22.5 & 55.8 & 60 \\
\hline & 2021 & 68 & 60 & 50 & 50 & 40 & 25 & 20 & 25 & 32 & 36 & 52 & 61 \\
\hline & $\begin{array}{c}\text { U.Y. } \\
\text { Ort. }\end{array}$ & 71.6 & 66.1 & 69.0 & 63.0 & 47.0 & 25.1 & 21.0 & 27.6 & 30.5 & 38.3 & 50.7 & 65.5 \\
\hline
\end{tabular}

\section{BULGULAR ve TARTIŞMA}

İncelenen bazı agronomik özelliklerine ait varyans analiz tablosu Çizelge 3.'te verilmiştir. Buna göre, tane verimi, çiçeklenme gün sayısı, olgunlaşma gün sayısı, ilk bakla yüksekliği ve bitki boyu bakımından genotipler arasındaki fark istatistiki anlamda önemli $(\mathrm{P}<0.01)$ bulunmuştur.

Çizelge 3. İncelenen bazı agronomik özelliklere ait varyans analiz tablosu

\begin{tabular}{|c|c|c|c|c|c|c|c|c|c|c|c|}
\hline & & \multicolumn{2}{|c|}{ Tane Verimi } & \multicolumn{2}{|c|}{$\begin{array}{l}\text { Çiçeklenme Gün } \\
\text { Sayıs1 }\end{array}$} & \multicolumn{2}{|c|}{$\begin{array}{l}\text { Olgunlaşma Gün } \\
\text { Sayıs1 }\end{array}$} & \multicolumn{2}{|c|}{$\begin{array}{l}\text { İlk Bakla } \\
\text { Yüksekliği }\end{array}$} & \multicolumn{2}{|c|}{ Bitki Boyu } \\
\hline Kaynak & SD & KT & 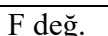 & $\mathrm{KT}$ & F de ğ. & KT & 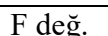 & KT & 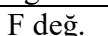 & KT & $\mathrm{F}$ değ. \\
\hline Çeşit & 6 & 9071,4 & $8,70^{* *}$ & 136 & $39,7 * *$ & 140 & $75,6^{* *}$ & 9,71 & $5,67 * *$ & 18 & $5,25 * *$ \\
\hline Tek & 1 & 257,1 & 1,48 öd & 0,1 & 0,13 öd & 1,1 & 3,7 öd & 0,16 & 0,56 öd & 0,07 & 0,13 öd \\
\hline Hata & 6 & 1042,9 & & 3,4 & & 1,9 & & 1,71 & & 3,43 & \\
\hline Genel & 13 & 10371 & & 139,5 & & 143 & & 11,6 & & 21,5 & \\
\hline $\mathrm{CV}(\%)$ & & & & 0,5 & & 0,3 & & & & & \\
\hline
\end{tabular}


Çizelge 4. İncelenen bazı kalite özelliklerine ait varyans analiz tablosu

\begin{tabular}{|c|c|c|c|c|c|c|c|c|c|c|c|}
\hline & & \multicolumn{2}{|c|}{ Kuru Ağırlık } & \multicolumn{2}{|c|}{ Yaş Ağırlık } & \multicolumn{2}{|c|}{ Kuru Hacim } & \multicolumn{2}{|c|}{ Yaş Hacim } & & \\
\hline Kaynak & SD & KT & F değ. & KT & F değ. & KT & $F$ değ. & KT & F değ. & KT & F değ. \\
\hline Çeşit & 6 & 3,214 & $21,6^{* *}$ & 12,24 & $79,3 * *$ & 67,86 & $27,9 * *$ & 75,4 & $15,5^{* *}$ & & \\
\hline Tek & 1 & 0,011 & 0,46 öd & 0,00 & 0,03 öd & 0,07 & 0,18 öd & 0,64 & 0,8 öd & & \\
\hline Hata & 6 & 0,149 & & 0,15 & & 2,43 & & 4,86 & & & \\
\hline Genel & 13 & 3,374 & & 12,39 & & 70,36 & & 80,9 & & & \\
\hline $\mathrm{CV}(\%)$ & & & & & & & & & & & \\
\hline
\end{tabular}

İncelenen bazı kalite özelliklerine ait varyans analiz tablosu Çizelge 4'te verilmiştir. Buna göre, kuru ağırlık, yaş ağıllık, kuru hacim ve yaş hacim özellikleri bakımından genotipler arasındaki fark istatistiki anlamda önemli $\quad(\mathrm{P}<0.01)$ bulunmuştur.

Çizelge 5. Agronomik özelliklere ait ortalama değerler

\begin{tabular}{|l|l|l|l|l|l|}
\hline & TV $(\mathrm{kg} / \mathrm{da})$ & ÇGS (Gün) & OGS (Gün) & İBY $(\mathrm{cm})$ & BB $(\mathrm{cm})$ \\
\hline Firat-87 & $250 \mathrm{a}$ & $161,5 \mathrm{~b}$ & $182,5 \mathrm{e}$ & $18,3 \mathrm{ab}$ & $31,0 \mathrm{ac}$ \\
\hline Şakar & $235 \mathrm{ab}$ & $158,5 \mathrm{c}$ & $184,5 \mathrm{~d}$ & $16,8 \mathrm{c}$ & $30,0 \mathrm{bd}$ \\
\hline Çağ11 & $235 \mathrm{ab}$ & $161,5 \mathrm{c}$ & $186,5 \mathrm{c}$ & $18,5 \mathrm{a}$ & $32,5 \mathrm{a}$ \\
\hline Altıntoprak & $215 \mathrm{bc}$ & $158,5 \mathrm{c}$ & $180 \mathrm{f}$ & $16,5 \mathrm{c}$ & $29,0 \mathrm{~d}$ \\
\hline Midyat-1 & $220 \mathrm{ab}$ & $166,5 \mathrm{a}$ & $189,5 \mathrm{a}$ & $17,0 \mathrm{bc}$ & $31,5 \mathrm{ab}$ \\
\hline Midyat-2 & $185 \mathrm{~cd}$ & $165,5 \mathrm{a}$ & $188,5 \mathrm{ab}$ & $16,3 \mathrm{c}$ & $29,5 \mathrm{~cd}$ \\
\hline Midyat-3 & $175 \mathrm{~d}$ & $165,5 \mathrm{a}$ & $187,5 \mathrm{bc}$ & $16,5 \mathrm{c}$ & $30,0 \mathrm{bd}$ \\
\hline ORT & 216,43 & 162,5 & 185,6 & 17,11 & 30,5 \\
\hline AÖF & & $1,85^{* *}$ & $1,36^{* *}$ & & \\
\hline
\end{tabular}

Tane verimine ait ortalama değerler ve istatistiki gruplar Çizelge 5'te verilmiştir. Buna tane verimi $175 \mathrm{~kg} / \mathrm{da}$ (Midyat-3) ile $250 \mathrm{~kg} / \mathrm{da}$ (Fırat-87) arasında değişmiş, genotiplere ait ortalama değer $216.43 \mathrm{~kg} / \mathrm{da}$ olarak tespit edilmiştir. Çalışmada kullanılan yerel Midyat-1 genotipi 220 $\mathrm{kg} / \mathrm{da}$ ile Güneydoğu Anadolu Bölgesinde yoğun ekime alanına sahip Fırat-87, Şakar ve Çağıl ıslah çeşitlerine yakın veya yarışabilecek tane verimi değerine sahip olmuştur. Diğer yerel çeşitler Midyat-2 ve Midyat-3 genotipleri ise slah çeşitlerine kıyasla çok daha düşük tane verimi değerlerine sahip olmuşlardır. Çalışmada kullanılan yerel çeşitlerin popülasyon veya aynı özelliklere sahip saf bir genotipten ibaret olup olmadığı konusu bilinmemekte olup, bu yerel çeşitler içerisinden tek bitki seçimi yapılması yolu ile ıslah çalışmalarının yapılması gerektiği kanaatindeyiz. Ninou ve ark. (2019) yerel mercimek çeşitleri ile ilgili yaptığı çalışmada, popülasyon halindeki tane verimi ile aynı popülasyon içerisinden seçilmiş tek bitkilerin tane verimini ve kalite değerlerini incelediği çalışmada; popülasyon içerisinden seçilen tek bitkilerden bazılarının popülasyondan daha yüksek tane verimine sahip olduğunu, fakat çoğu tek bitkinin popülasyondan daha düşük tane verimine sahip olduğunu ve popülasyon içerisinden teksel seçimde çok dikkatli olunması gerektiği belirtilmiştir. Toklu ve ark, (2009) Güneydoğu Anadolu Yerel Kırmızı Mercimek çeşitleri konusunda yaptığı çalışmasında, yerel çeşitlerin verim ve verim komponentleri bakımından geniş bir varyasyona sahip olduğunu, bu yerel çeşitler içerisinden seçilecek tek bitkilerin 1slah amacına uygun olarak kullanılabilecek potansiyele sahip olduklarını belirtmiştir.

Çiçeklenme gün sayısına ait ortalama değerler ve istatistiki gruplar Çizelge 5'te verilmiştir. Buna çiçeklenme gün sayısı 158.5 gün (Altıntoprak ve Şakar) ile 166.5 gün (Midyat-1) değişmiş, genotiplere ait 
ortalama değer 162.5 gün olarak tespit edilmiştir. Elde edilen sonuçlara göre yerel genotiplerin daha uzun çiçeklenme gün sayısına sahip olduğu ve bunun yerel genotplerin gün uzunluğuna hassasiyeti ile ilgili olduğunu, yerel çeşitlerin daha uzun 1şıklanma süresi sonunda çiçeklendiğini göstermektedir. Koç ve Akdeniz (2019) Güneydoğu Anadolu ekolojik koşullarında yaptıkları çalışmada, kırmızı mercimek çeşitlerinin \% 50 çiçeklenme gün sayısının 158 (Tigris) gün ile 164 (Seyran) gün arasında değiştiğini bildirmiştir

Olgunlaşma gün sayısına ait ortalama değerler ve istatistiki gruplar Çizelge $5^{\prime}$ te verilmiştir. Elde edilen verilere göre olgunlaşma gün sayısı 180 gün (Altıntoprak) ile 189.5 gün (Midyat-1) arasında değişmiş, ortalama değer 185.6 gün olarak kaydedilmiştir. Olgunlaşma gün sayıs1 bakımından yerel mercimek genotipleri 1slah çeşitlerinden daha geç hasada geldikleri tespit edilmiştir. Olgunlaşmanın erken zamanda gerçekleşmesi yüksek sıcaklık, kuraklık ve çeşitli stres faktörlerinden daha düşük oranda etkilenmesine olanak sağlarken, özellikle vejetasyon süresinin daha uzun sürdüğü sezonlarda geççi genotiplerin tane verimini olumlu etkilemektedir (Çokkızgın ve ark., 2007; Aydoğan ve ark., 2008 ).

İlk bakla yüksekliğine ait ortalama değerler ve istatistiki gruplar Çizelge $5^{\text {t }}$ te verilmiştir. Buna göre ilk bakla yüksekliği $16.3 \mathrm{~cm}$ (Midyat-2) ile $18.5 \mathrm{~cm}$ (Çağıl) arasında değişmiş, ortala değer ise $17.11 \mathrm{~cm}$ olarak tespit edilmiştir. İlk bakla yüksekliği hasat zamanında tane veya bakla dökülmesine etki eden bir faktör olup, makinalı hasat için ilk bakla yüksekliği değerinin yüksek olması arzu edilmektedir
(Biçer ve Şakar, 2011). Bu çalışmada, ilk bakla yüksekliği değeri bakımından ıslah çeşitlerinin yerel Midyat Mercimek çeşitlerinden daha yüksek değerlere sahip olması 1slah çalışmalarının bir çıktısı olarak değerlendirilebilir. Yerel mercimek genotipleri veya popülasyonu içerisinden ilk bakla yüksekliği bakımından istenilen özelliklere sahip genotiplerin seleksiyon 1slahı ile tespiti veya mercimek sslah programları kapsamında ıslah çeşitleri ile yerel çeşitler arasında yapılacak melezlemelerle arzu edilen genotiplerin geliştirilmesi bitki ıslahı çalışmalarının amaçlarından birisi olup, bu anlamda değerli gen kaynakları olarak değerlendirilmesi gerekmektedir. Buğday, arpa ve misır gibi diğer tahıl türleri ile k1yasla mercimek ve nohutun makineli hasat edilmesi yakı zamanlarda gerçekleştiği göz önüne alındığında yerel çeşitlerin ilk bakla yüksekliği bakımından 1slah çeşitlerinden düşük değerlere sahip olması beklenen bir durumdur. Zira, mercimek ve nohut hasadı yakın geçmişe kadar elle yapılmaktaydı tane kayıpları söz konusu değildi.

Çalışmada kullanılan genotiplerin bitki boyuna ait ortalama değerler ve istatistiki

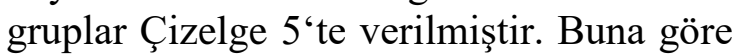
bitki boyu $29 \mathrm{~cm}$ (Altıntoprak) ile $32.5 \mathrm{~cm}$ (Çağıl) arasında değişmiş, ortala değer ise $30.5 \mathrm{~cm}$ olarak tespit edilmiştir. Yerel Midyat-1 populasyonu $31.5 \mathrm{~cm}$ ile ikinci en yüksek bitki boyu değerine sahip olmuştur. Bitki boyu ilk bakla yüksekliği ile beraber değerlendirildiğinde makinalı hasada uygunluk bakımından önemli bir parametre olup, makinalı hasada uygun genotiplerin geliştirilmesi 1slah amaçlarından birisidir (Biçer ve Şakar, 2011)

Çizelge 6. Elek analizi sonuçları

\begin{tabular}{|l|l|l|l|l|}
\hline Çeşit & $5 \mathrm{~mm}$ & $4,5 \mathrm{~mm}$ & $4 \mathrm{~mm}$ & $3,5 \mathrm{~mm}$ \\
\hline Firat-87 & 0 & 60 & 30 & 10 \\
\hline Altıntoprak & 0 & 70 & 25 & 5 \\
\hline Çağıl & 0 & 78 & 19 & 3 \\
\hline Şakar & 30 & 56 & 12 & 2 \\
\hline Midyat-1 & 35 & 53 & 10 & 2 \\
\hline Midyat-2 & 37 & 56 & 10 & 1 \\
\hline Midyat-3 & 36 & 9 & 2 \\
\hline
\end{tabular}


Çalışmada kullanılan genotiplere ait elek analizi sonuçları Çizelge 6'da verilmiştir. Elek analizi daha çok tohumların fiziki özellikleri (şekil, irilik, tohum kalınlığg, uzunluğu, çap1 vb) ile ilişkili olup, mercimek tanesinin işleme aşamasında ve son ürüne dönüştürülme aşamasında oluşacak kayıpların belirlenmesinde kullanılmaktadır (Alabay, 2019). Elek analizinde elde edilen sonuçlara göre, $5 \mathrm{~mm}$ elekte en fazla oranda tohum oranı Midyat2, Midyat-3 ve Midyat-1 yerel mercimek genotiplerinden (\%37; \%36 ve \%35) elde edilmiştir. Islah çeşitleri olan Çağıl, Altıntoprak ve Firat-87 genotiplerinde 4.5 mm elek üstü tane oranı sırasıyla $\% 78, \% 70$ ve \% 60 olarak daha yüksek değerlere ulaşırken, $5 \mathrm{~mm}$ ve $4.5 \mathrm{~mm}$ toplamında oran olarak Midyat yerel çeşitlerinin 1slah çeşitlerinden daha yüksek değerlere ulaştığı ve işleme aşamasında bu yerel çeşitlerin kayıp oranının daha az olacağı anlaşılmaktadır.

Çizelge 7. İncelenen kalite özelliklerine ait ortalama değerler

\begin{tabular}{|l|l|l|l|l|}
\hline & KA & YA & KH & YH \\
\hline Firat-87 & $3,85 \mathrm{c}$ & $7,20 \mathrm{~d}$ & $53,5 \mathrm{bc}$ & $106,5 \mathrm{~d}$ \\
\hline Şakar & $4,55 \mathrm{~b}$ & $8,70 \mathrm{~b}$ & $54,5 \mathrm{~b}$ & $109,0 \mathrm{bc}$ \\
\hline Çağ1 & $3,95 \mathrm{c}$ & $7,55 \mathrm{~cd}$ & $53,0 \mathrm{bc}$ & $106,0 \mathrm{~d}$ \\
\hline Altıntoprak & $4,00 \mathrm{c}$ & $7,80 \mathrm{c}$ & $52,5 \mathrm{c}$ & $107,0 \mathrm{~cd}$ \\
\hline Midyat-1 & $5,05 \mathrm{a}$ & $9,45 \mathrm{a}$ & $57,5 \mathrm{a}$ & $111,0 \mathrm{ab}$ \\
\hline Midyat-2 & $5,00 \mathrm{a}$ & $9,55 \mathrm{a}$ & $57,5 \mathrm{a}$ & $110,5 \mathrm{ab}$ \\
\hline Midyat-3 & $4,80 \mathrm{ab}$ & $9,50 \mathrm{a}$ & $58,0 \mathrm{a}$ & $112,5 \mathrm{a}$ \\
\hline ORT & 4,46 & 8,54 & 55,21 & 108,93 \\
\hline AÖF & & & & \\
\hline
\end{tabular}

Çalışmada genotiplerin incelenen bazı kalite özelliklerine ait ortalama değerler ve istatistiki gruplar Çizelge 7'de verilmiştir. Kuru ağırlı̆ga ait ortalama değerler ve istatistiki gruplar Çizelge 8.'de verilmiştir. Buna göre kuru ağırlık 3.85 g (Fırat-87) ile $5.05 \mathrm{~g}$ (Midyat-1) arasında değișmiş, ortala değer ise $4.46 \mathrm{~g}$ olarak tespit edilmiştir. Elde edilen sonuçlara göre tüm yerel kırmızı mercimek çeşitlerinin kuru ağırlık bakımından tüm 1slah çeşitlerine üstünlük gösterdiği görülmektedir. Daha önce yapılan çalışmalarda, yerel mercimek çeşitleri içerisinde tohum iriliği, kuru ağırlık ve diğer kalite özellikleri bakımından geniş bir varyasyon olduğu ve bu genetik kaynaklardan 1slah programlarında yararlanılması gerektiğ i vurgulanmıştır. (Tsanakasi ve ark., 2018; İdrissi ve ark., 2015; Horneburg ve ark., 2008) Kuru ağırlık bakımından bu yerel çeşitlerden yararlanmak için bu çeşitlerin 1slah programlarında tek bitki seçimlerinin yapılarak yeni çeşitlerin geliştirilmesi veya bu yerel çeşitlere ait tek bitkilerin melezleme çalışmalarında genitör olarak kullanılması yolu ile bu özelliklerinin ıslah çeşitlerine aktarılması önerisi yapılabilir. Ninou ve ark. (2019) Yunanistan'a yerel mercimek çeşitlerinin popülasyon ve bu popuasyonlardan seçilmiş tek bitkilerin tane verimi ve kalite özelliklerini incelediği çalışmada, tek bitkilerin kuru madde oranının \%3.21 ile \%6.94 arasında değiştiğini ve elde edilen souçlara göre tek bitkilerin kuru madde oranının popülasyona göre $\% 30$ ile $\% 110$ arasında daha yüksek olduğunu, yüksek tane verimine sahip tek bitkilerin popülasyon ile yakın kuru madde değerlerşne sahip olduğunu, buna karşın tek bitkilerden 2-S1-El-10 genotipinin kuru madde oranının popülasyondan \% 73 oranında daha yüksek kuru maddeye sahip olduğunu tespit ettiklerini belirtmiştir.

Yaş ağırlı̆̆a ait ortalama değerler ve istatistiki gruplar Çizelge 7'de verilmiştir. 
Buna göre kuru ağırlık 7.20 g (Fırat-87) ile $9.55 \mathrm{~g}$ (Midyat-2) arasında değişmiş, ortala değer ise $8.54 \mathrm{~g}$ olarak tespit edilmiştir. Elde edilen sonuçlara göre, yaş ağırlık bakımından yerel kırmızı mercimek genotipleri, tüm ıslah çeşitlerine üstünlük göstermiştir. Bu yerel çeşitler, kalite değeri yüksek mercimek çeşitlerinin geliştirilmesinde genitör olarak kullanılabileceği gibi, aynı zamanda bu yerel çeşitler içerisinden tek bitki seçimi ile kalite değeri yüksek mercimek çeşitlerinin geliştirilmesi olanağı sunmaktadır. Elde edilen veriler çalışmaya konu olan yerel kırmızı mercimek çeşitlerinin bölgedeki tüketiciler tarafindan tercih edilme nedenlerini doğrulamaktadır.

Kuru hacime ait ortalama değerler ve istatistiki gruplar Çizelge 7'de verilmiştir. Buna göre kuru hacim $52.5 \mathrm{ml}$ (Altıntoprak) ile $58 \mathrm{ml}$ (Midyat-3) arasında değişmiş, ortala değer ise $55.21 \mathrm{ml}$ olarak tespit edilmiştir. Elde edilen sonuçlara göre, kuru hacim bakımından yerel kırmzı mercimek genotipleri, tüm 1slah çeşitlerinden daha yüksek değerlere sahip olduğu tespit edilmiştir.

Yaş hacime ait ortalama değerler ve istatistiki gruplar Çizelge 7'de verilmiştir. Buna göre kuru hacim 106 ml (Çağıl) ile $112.5 \mathrm{ml}$ (Midyat-3) arasında değişmiş, ortala değer ise $108.93 \mathrm{ml}$ olarak tespit edilmiştir. Elde edilen sonuçlara göre, yaş hacim bakımından yerel kırmızı mercimek genotipleri, tüm 1slah çeşitlerinden daha yüksek değerlere sahip olduğu tespit edilmiştir.

\section{SONUÇ ve ÖNERILER}

Yapılan çalışma sonucunda, yerel Midyat kırmızı mercimek çeşidi olarak isimlendirilen pouplasyonların, kuru ağılık, yaş ağırlık, kuru ve yaş hacim değerleri bakımından standart çeșitlerden üstün özellikler taşıdığı, özellikle kalite değerleri yüksek mercimek çeşitlerinin geliştirilmesinde bu yerel çeşitlerin içerisinden yapılacak tek bitkilerin direk olarak kullanılması veya bunların genitör olarak 1slah programlarında kullanılabilecek özelliklere sahip olduğu, bu değerli genetik kaynağın korunması, tanitılması ve bu konuda daha kapsaml çalışmaların yapılmasının gerektiği sonucuna varılmıştır. Midyat yerel kırmızı mercimek çeşidinin ülkemiz Kırmızı Mercimek ticaretinde büyük katkılar yapma potansiyeli olabileceği öngörülmüştür.

\section{KAYNAKLAR}

Alabay, F. 2019. Kışlık ve yazlık mercimek (Lens culinaris Medik. ) ekiminde yabanc1 ot yoğunluğu ile verim ve kalite ögelerinin belirlenmesi. Ankara Üniversitesi Fen Bilimleri Enstitüsü Yüksek Lisans Tezi. (1-73)

Anonim, 2021. http://fao.org/faostat/data/ QC (Erişim tarihi: 10.04.2021).

Aydoğan, A., Karagül, V., Gürbüz, A., 2008. Araştırma makalesi farklı ekim zamanlarının yeşil ve kırmızı mercimeğin (Lens culinaris Medik.) verim ve verim öğelerine etkileri. Tarla Bitkileri Merkez Araştırma Enstitüsü Dergisi, 17(1-2):

Bahl, P.N., Lal, S., Sharma, B.M. 1991. An overview of the production and problems in South East Asia. In Lentil in South Asia, Proceedings of the Seminar on Lentils in South Asia, New Delhi, India, 11-15 March 1991; Erskine, W., Saxena, M.C., Eds.; ICARDA: Aleppo, Syria, 1993; pp. 1-10.

Biçer, T.B., Şakar, D. 2011. Mercimek (Lens culinaris Medik.) hatlarının verim ve verim özellikleri yönünden değerlendirilmesi. Harran Ü.Z.F. Dergisi, 15(3): 21-27.

Çokkızgın, A., Anlarsal A.E. 2007. Güney ve güneydoğu anadolu bölgelerinden toplanan bazı kırmızı mercimek (Lens culinaris Medik.) yerel genotiplerinin bitkisel ve tarımsal özelliklerinin belirlenmesi üzerine bir araştırma. Çukurova Üniversitesi Fen Bilimleri Enstitüsü, Doktora Tezi.

Düzgün, Z.E., Toğay, N . 2021. The Effects of Different Planting Densities on Lentil (Lens culinaris Medic.) Yield and Yield Components in Mardin Conditions. 
ISPEC Tarım Bilimleri Dergisi 5(3): 560567.

Erman, M., Çı̆̆,F., Ceritoğlu, F., Ceritoğlu, M. 2021. Evaluation of Early Stage Traits as an Indicator of Genetic

Variation in Winter Lent. ISPEC Journal of Agricultural Sciences, 5(3):552-559.

Horneburg, B and Becker, HC. 2008. Crop adaption in on-farm management by natural and conscious selection: a case study with lentil. Crop Science 48: 203212.

Idrissi, O., Udupa, SM., Houasli, C., Keyser, ED., Van Damme, P and De Riek, J. 2015. Genetic diversity analysis of Moroccan lentil (Lens culinaris Medik.) landraces using simple sequence repeat and amplified fragment length polymorphisms reveals functional adaptation towards agroenvironmental origins. Plant Breeding 134: 322-332.

Ninou, E., Papathanasiou, F., Vlachostergios, D.N., Mylonas, L., Kargiotidou, A., Pankou, C., Papadopoulos, L., Sinapidou, E., Tokatlidis, L. 2019. Intense Breeding within Lentil Landraces for High-Yielding Pure Lines Sustained the
Seed Quality Characteristics. Agriculture (9): 175-188.

Özer, M.S, Kaya, F. 2010. Physical, chemical and physicochemical properties of some lentil varieties grown in Turkey. J. Food Agric. Environ., 8: 610-613.

Tsanakasi, G.S., Mulona, P.V., Koura, K., Gleridou, A., Polidorosi, A.N. 2018. Genetic diversity analysis of the Greek lentil (Lens culinaris Medik.) landrace 'Eglouvis' using morphological andmolecular markers. Plant Genetic Resources, 16(5):

Toklu, F., Bicer, B.T., Karakoy, T., 2009. Agro-morphological characterization of the Üniversitesi Turkish lentil landraces. African Journal of Biotechnology, 8(17):4121-4127.

Vlachostergios, D.N, Tzantarmas, C, Kargiotidou, A, Ninou, E, Pankou, C, Gaintatzi, C.,Mylonas, I, Papadopoulos, I, Foti, C, Chatzivassiliou, E.K. 2018. Singleplant selection within lentil landraces at ultra-low density: A short-time tool to breed high yielding and stable varieties across divergent environments. Euphytica., 214: $58-72$. 